\title{
Molecular Response of Chronic Myeloid Leukaemia Patients to Tyrosine Kinase Inhibitors
}

\author{
*Hossain MI ${ }^{1}$, Yamani $\mathrm{MJ}^{2}$, Hossain $\mathrm{M} \mathrm{G}^{3}$, Hossain $\mathrm{MM}^{4}$, Khan M R ${ }^{5}$, Aziz MA ${ }^{6}$
}

\begin{abstract}
Background: The goal of therapy in Chronic Myeloid Leukaemia (CML) with tyrosine kinase inhibitors (TKIs) has been to achieve the molecular responses, as measured by the reduction or elimination of $B C R-A B L_{l}$ transcript. Objective: The aim of the study is to observe the molecular response status of CML patients to TKIs. Methodology: This is an observational study and was conducted in the department of Haematology, Bangabandhu Sheikh Mujib Medical University (BSMMU) from February 2018 to January 2019. A total of 30 diagnosed CML patients on TKIs therapy was checked for quantitative BCR-ABL 1 (by qRT-PCR) level. The laboratory monitoring of $B C R-A B L_{1} R N A$ with $R Q-P C R$ was likely become the model for successful molecular diagnostic monitoring of CML patients to both assess and prognosticate the efficacy of these targeted treatments. Result: Among 30 diagnosed CML patients, the mean age was found $36.1 \pm 11.7$ years with range from 20 to 70 years. Males were predominant 19 (63.3\%), male: female ratio was 1.7:1. Almost two third (63.3\%) patients were found optimal ( $\leq 10 \%)$ after 3-month BCR ABL. Age, sex, religion, marital status, occupational status, BMI, monthly income, number of family member, symptoms and sings were not statistically significant ( $p>0.05)$ when compared between $B C R$ ABL optimal $(\leq 10 \%)$ and warning $(>10 \%)$ group. Mean haemoglobin, total leukocyte count, platelet count, basophil, myelocyte and baseline BCR $A B L 1$ were not statistically significant $(p>0.05)$ however atypical cells was found statistically significant $(p<0.05)$ when compared between BCR-ABLI optimal and warning group. Conclusion: In conclusion, the present study confirms that early molecular monitoring at 3 months after imatinib initiation helps in predicting the concurrent cytogenetic response and treatment optimization in CML patients.
\end{abstract}

Key wards: $\mathrm{Ph}$ chromosome, $\mathrm{CML}, \mathrm{BCR}-\mathrm{ABL}_{1}$ fusion gene, tyrosine kinase inhibitors, RQ-PCR, minimal residual disease, qRT-PCR, CCyR.

\section{Introduction}

In the present arena of targeted therapy, tyrosine kinase inhibitors (TKIs), specifically imatinib, is the recommended first-line treatment for patients with newly diagnosed CML which dramatically improved

\section{Author's}

1. *Md. Imran Hossain, Department of Haematology, Bangabandhu Sheikh Mujib Medical University (BSMMU), Shahbag, Dhaka, Bangladesh.

2. Md. Jaki Yamani, Department of Haematology, Bangabandhu Sheikh Mujib Medical University, Dhaka, Bangladesh.

3. Md. Golzar Hossain, Department of Haematology, National Institute of Cancer Research and Hospital, Dhaka, Bangladesh.

4. Mohammed Murad Hossain, Department of Haematology, Bangabandhu Sheikh Mujib Medical University, Dhaka, Bangladesh.

5. Md. Rafiquzzaman Khan, Department of Haematology, Bangabandhu Sheikh Mujib Medical University, Dhaka, Bangladesh.

6. Md. Abdul Aziz, Department of Haematology, Bangabandhu Sheikh Mujib Medical University, Dhaka, Bangladesh.

*Correspondence: Md. Imran Hossain, Department of Haematology, Bangabandhu Sheikh Mujib Medical University (BSMMU), Shahbag, Dhaka, Bangladesh.

e-mail: dr.imranhaemato@gmail.com, Contact: +880 1711-958930. Page | 42 the 8-year survival rates of CML patients to $85 \%$ with proper molecular monitoring. ${ }^{1-2}$ Quantitative Real time Polymerase Chain Reaction (RQ-PCR) is approximately three logs more sensitive than cytogenetic techniques, and it is typically able to detect one leukaemia cell in a background of approximately 100,000 normal cells is the main molecular monitoring tool for disease process in CML using peripheral blood samples rather bone marrow sampling and correlates well with clinical response. ${ }^{3-4}$ The European Leukaemia Net and the National Comprehensive Cancer Network recommend RQ-PCR-based molecular monitoring every 3 months until a deep response i.e. major molecular response (MMR) or Complete Cytogenetic Response (CCyR) occurs and every 3-6 months thereafter. ${ }^{1}$ MMR achieved in approximately $50 \%$ of imatinib-treated patients within 12 months, is also associated with a longer duration of CCyR. ${ }^{5}$ On the other hand, the failure to achieve an MMR after 12 months with first line TKI therapy is considered a 'warning sign'. ${ }^{1}$

Haematol J Bangladesh 2019; 3(2):42-46 
In Bangladesh, patients with economic constraints restrain physician to ask for the test according to recommended guidelines. Besides only a handful number of patients are taking TKIs regularly, many are least compliant in taking TKIs for the cost. Considering these entire pitfalls, the present study can draw a glimpse on the disease status and response to TKIs therapy. Moreover, this can reflect the number of patients achieving early molecular response and current response status of patients to TKIs. Almost no study has done till date regarding assessment of monitoring and progression of disease, response to treatment and expected survival among CML patients. Therefore, we have conducted this study to observe the molecular response status of CML patients to TKIs.

\section{Materials and Methods}

This was a cross sectional observational study conducted in the department of Haematology, BSMMU from February 2018 to January 2019. Using purposive sampling method, a total of 30 diagnosed CML patients were enrolled. Patients who were pregnant/lactating, whose age were less than 18 years, who were taking medications other than TKIs, and non-complaint to the TKI therapy were excluded from the study. The study population on TKIs therapy was checked for quantitative BCR-ABL 1 (by qRT-PCR) level at 3-month of starting TKI. Data were collected using a semi-structured questionnaire. We have collected our data on patients' demographic variables which includes age, sex, weight, height and body mass index and also disease variables which includes BCR-ABL, baseline leukocyte count, CML morphological type. The laboratory monitoring of BCR-ABL RNA with RQ- PCR was likely become the model for successful molecular diagnostic monitoring of CML patients to both assess and prognosticate the efficacy of these targeted treatments. Informed consent was taken from the subjects. Participants were having every right to withdraw themselves from the study at any point of time. Ethical issues were addressed to every patient. Ethical clearance was obtained from institutional review board (IRB) of BSMMU. Quality assurance measurements were taken with every instrument.

\section{Results}

In this observational study we enrolled 30 cases of CML patients to see the response of TKIs at 3 months

Haematol J Bangladesh 2019; 3(2):42-46 after initiation. Majority $(46.7 \%)$ patients belonged to age $\leq 30$ years. The mean age was found $36.1 \pm 11.7$ years with range from 20 to 70 years. Almost wo third $(63.3 \%)$ patients were male and $11(36.7 \%)$ patients were female. Male female ratio was 1.7: 1. (Table:1)

Table 1: Distribution of the study patients by demographic characteristics $(n=30)$

\begin{tabular}{lc}
\hline Age and sex distribution & $\mathbf{n}(\boldsymbol{\%})$ \\
\hline Age (in year) & \\
$\leq 30$ & $14(46.7)$ \\
$31-50$ & $13(43.3)$ \\
$>50$ & $3(10)$ \\
Mean \pm SD & $36.1 \pm 11.7$ \\
Range (min-max) & $20.0-70.0$ \\
Sex & \\
Male & $19(63.3)$ \\
Female & $11(36.7)$ \\
\hline
\end{tabular}

In this series it was observed that all $(100.0 \%)$ patients had splenomegaly, $22(73.3 \%)$ had anaemia and 12 $(40.0 \%)$ had hepatomegaly.

Almost three fourth $(73.3 \%)$ patients had total leukocyte count $101-250 \times 10^{9} / \mathrm{L}$. The mean total leukocyte count was found $175.2 \pm 90.1 \times 10^{9} / \mathrm{L}$ with range from 3.5 to $460.0 \times 10^{9} / \mathrm{L}$. The mean haemoglobin was $9.63 \pm 1.62 \mathrm{~g} / \mathrm{dl}$ with range from 6.5 to $12.7 \mathrm{~g} / \mathrm{dl}$. Majority $(46.7 \%)$ patients had platelet count $\leq 400 \mathrm{x}$ $10^{9} / \mathrm{L}$. The mean platelet count was found $468.5 \pm$ $211.6 \times 10^{9} / \mathrm{L}$ with range from 160.0 to $1000.0 \mathrm{x}$ 109/L. Majority (80.0\%) patients had basophil 2-5\%. The mean basophil was found $3.8 \pm 1.8 \%$ with range from 2.0 to $8.0 \%$. Almost half $(46.7 \%)$ of patients had myelocyte $>20 \%$. The mean myelocyte was found $21.4 \pm 9.3 \%$ with range from 6.0 to $40.0 \%$. Majority $(80.0 \%)$ patients had atypical cells $\leq 4 \%$. The mean atypical cells were found $3.6 \pm 2.0$ percent with range from 1.0 to $10.0 \%$. (Table:2)

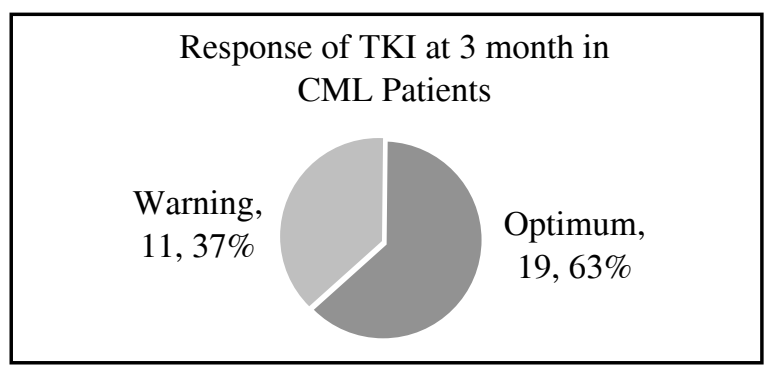

Figure 1: Response of TKI at 3 months in CML patients.

Page | 43 
Original Article

Table 2: Distribution of the study patients according to initial laboratory investigation $(n=30)$

\begin{tabular}{|c|c|c|}
\hline Initial laboratory investigation & & $\mathrm{n}(\%)$ \\
\hline \multicolumn{3}{|l|}{ Total leukocyte count (x 109/L) } \\
\hline$\leq 100$ & & $3(10.0)$ \\
\hline $101-250$ & & $22(73.3)$ \\
\hline $251-400$ & & $4(13.3)$ \\
\hline$>400$ & & $1(3.3)$ \\
\hline Mean \pm SD & \multicolumn{2}{|l|}{$175.2 \pm 90.1$} \\
\hline Range (min-max) & \multicolumn{2}{|l|}{$3.5-460.0$} \\
\hline \multicolumn{3}{|l|}{ Haemoglobin (g/dl) } \\
\hline Mean \pm SD & \multicolumn{2}{|l|}{$9.63 \pm 1.62$} \\
\hline Range (min-max) & \multicolumn{2}{|l|}{$6.5-12.7$} \\
\hline \multicolumn{3}{|l|}{ Platelet count $\left(\mathbf{x 1 0}^{9} / \mathrm{L}\right)$} \\
\hline$\leq 400$ & & $14(6.7)$ \\
\hline $401-600$ & & $10(33.3)$ \\
\hline$>600$ & & $6(20.0)$ \\
\hline Mean \pm SD & \multicolumn{2}{|l|}{$468.5 \pm 211.6$} \\
\hline Range (min-max) & \multicolumn{2}{|l|}{$160.0-1000.0$} \\
\hline \multicolumn{3}{|l|}{ Basophil (\%) } \\
\hline $2-5$ & & $24(80.0)$ \\
\hline $6-10$ & & $6(20.0)$ \\
\hline Mean \pm SD & \multicolumn{2}{|l|}{$3.8 \pm 1.8$} \\
\hline Range (min-max) & \multicolumn{2}{|l|}{$2.0-8.0$} \\
\hline \multicolumn{3}{|l|}{ Myelocytes (\%) } \\
\hline$\leq 10$ & & $6(20.0)$ \\
\hline $11-20$ & & $10(33.3)$ \\
\hline$>20$ & & $14(46.7)$ \\
\hline Mean \pm SD & \multicolumn{2}{|l|}{$21.4 \pm 9.3$} \\
\hline Range (min-max) & \multicolumn{2}{|l|}{$2.0-8.0$} \\
\hline \multicolumn{3}{|l|}{ Atypical cells } \\
\hline$\leq 4$ & & $24(80.0)$ \\
\hline $5-10$ & & $6(20.0)$ \\
\hline Mean \pm SD & \multicolumn{2}{|l|}{$3.6 \pm 2.0$} \\
\hline Range (min-max) & \multicolumn{2}{|l|}{$1.0-10.0$} \\
\hline
\end{tabular}

Out of $30 \mathrm{CML}$ patients, we found 19 (63\%) patent achieved optimal response with TKI therapy after 3 months by qRT-PCR observation. (Figure: 1) At diagnosis, no significant difference observed in \% BCR-ABL ${ }_{1}$ between optimal and warning group responders but after significant difference observed at 3 months after TKI therapy between two groups. (Table: 3)

Table 3: Response of TKI and percentage of BCR-ABL ${ }_{1}$ at diagnosis and after 3 months after TKI therapy. (n:30)

\begin{tabular}{|c|c|c|c|c|c|}
\hline \multirow{2}{*}{ BCR-ABL1 } & \multirow{2}{*}{ Response Group } & \multirow{2}{*}{$\mathrm{n}(\%)$} & \multicolumn{2}{|c|}{$\%$ of BCR-ABL 1} & \multirow{2}{*}{ P-value } \\
\hline & & & Mean \pm SD & Total; Mean \pm SD & \\
\hline \multirow{2}{*}{ At diagnosis } & Optimal: $\leq 10 \%$ & $19(63.33)$ & $61.53 \pm 20.65$ & \multirow{2}{*}{$67.27 \pm 18.83$} & \multirow{2}{*}{$0.069 \mathrm{~ns}$} \\
\hline & Warning:>10\% & $11(36.67)$ & $74.46 \pm 12.01$ & & \\
\hline \multirow{2}{*}{$\begin{array}{l}3 \text { months after } \\
\text { initiation of TKI }\end{array}$} & Optimal: $\leq 10 \%$ & $19(63.33)$ & $4.26 \pm 3.26$ & \multirow[t]{2}{*}{$14.96 \pm 17.36$} & \multirow[t]{2}{*}{$<0.001 \mathrm{~s}$} \\
\hline & Warning: $>10 \%$ & $11(36.67)$ & $33.45 \pm 16.18$ & & \\
\hline
\end{tabular}

Mean age was found $34.3 \pm 10.3$ years in optimal group and 39.1 13.9 years in warning group. More than half $(52.6 \%)$ patients were male in optima 1 group and Page | 44
$9(81.8 \%)$ in warning group. No significant difference ( $p>0.05$ ) observed between two groups in age and sex. (Table: 4)

Table 4: Association between age and sex with after 3-month BCR-ABL ${ }_{1}(\mathrm{n}=30)$

\begin{tabular}{lccc}
\hline Age (in year) & $\begin{array}{c}\text { Optimal: } \leq \mathbf{1 0 \%} \\
(\mathbf{n : 1 9 )} ; \mathbf{n}(\boldsymbol{\%})\end{array}$ & $\begin{array}{c}\text { Warning:>10\% } \\
(\mathbf{n : 1 1 )} \mathbf{n}(\mathbf{\%})\end{array}$ & P-value \\
\hline$\leq 30$ & $9(47.4)$ & $5(45.5)$ & \\
$31-50$ & $8(42.1)$ & $5(45.5)$ & \\
$>50$ & $2(10.5)$ & $1(9.1)$ & $0.289 \mathrm{~ns}$ \\
Mean \pm SD & $34.3 \pm 10.0$ & $39.1 \pm 13.9$ & \\
Range (min-max) & $20.0-55.0$ & $22.0-70.0$ & \\
Sex & & & \\
Male & $10(52.6)$ & $9(81.8)$ & $0.113 \mathrm{~ns}$ \\
Female & $9(47.4)$ & $2(18.2)$ & \\
\hline
\end{tabular}

Mean atypical cells was found $3.0 \pm 1.2$ percent in optimal group and $4.5 \pm 2.8$ percent in warning group. Which was statistically significant $(\mathrm{p}<0.05)$ but other initial laboratory investigation was not statistically significant ( $p>0.05)$ between two groups. (table: 5 )

Table 5: Association between initial laboratory investigation with after 3-month $\mathrm{BCR} \mathrm{ABL}_{1}(\mathrm{n}=30)$

\begin{tabular}{|c|c|c|c|}
\hline $\begin{array}{l}\text { Initial laboratory } \\
\text { investigation }\end{array}$ & $\begin{array}{c}\text { Optimal; } \leq 10 \% \\
(n=19)\end{array}$ & $\begin{array}{c}\text { Warning; }>10 \% \\
(\mathrm{n}=11)\end{array}$ & P-value \\
\hline \multicolumn{4}{|l|}{ Haemoglobin (g/dl) } \\
\hline Mean \pm SD & $9.74 \pm 1.68$ & $9.41 \pm 1.48$ & $0.593^{\mathrm{ns}}$ \\
\hline Range (min-max) & $6.5-12.7$ & $6.8-11.2$ & \\
\hline \multicolumn{4}{|c|}{ Total leukocyte count (x 109/L) } \\
\hline$\leq 100 ; \mathrm{n}(\%)$ & $3(15.8)$ & $0(0.0)$ & \\
\hline $101-250 ; \mathrm{n}(\%)$ & $12(63.2)$ & $10(90.9)$ & \\
\hline $251-400 ;$ n (\%) & $3(15.8)$ & $1(9.1)$ & $0.945^{\mathrm{ns}}$ \\
\hline$>400 ; \mathrm{n}(\%)$ & $1(5.3)$ & $0(0.0)$ & \\
\hline Mean \pm SD & $174.3 \pm 106.3$ & $176.7 \pm 56.6$ & \\
\hline Range (min -max) & $3.5-460.0$ & $130.6-319.5$ & \\
\hline \multicolumn{4}{|c|}{ Platelet count (x 109/L) } \\
\hline$\leq 400 ; \mathrm{n}(\%)$ & $11(57.9)$ & $3(27.3)$ & \\
\hline 401-600; n (\%) & $5(26.3)$ & $5(45.5)$ & \\
\hline$>600 ; \mathrm{n}(\%)$ & $3(15.8)$ & $3(27.3)$ & $0.205^{\mathrm{ns}}$ \\
\hline Mean \pm SD & $430.7 \pm 178.5$ & $533.6 \pm 255.3$ & \\
\hline Range (min-max) & $160.0-930.0$ & $170.0-1000.0$ & \\
\hline \multicolumn{4}{|l|}{ Basophil (\%) } \\
\hline $2-5$ & $15(78.9)$ & $9(81.8)$ & \\
\hline $6-10$ & $4(21.1)$ & $2(18.2)$ & $0.776^{\mathrm{ns}}$ \\
\hline Mean \pm SD & $3.7 \pm 1.8$ & $3.9 \pm 1.9$ & \\
\hline Range (min-max) & $2.0-7.0$ & $2.0-8.0$ & \\
\hline \multicolumn{4}{|l|}{ Myelocyte (\%) } \\
\hline$\leq 10$ & $5(26.3)$ & $1(9.1)$ & \\
\hline $11-20$ & $5(26.3)$ & $5(45.5)$ & \\
\hline$>20$ & $9(47.4)$ & $5(45.5)$ & $0.342^{\mathrm{ns}}$ \\
\hline Mean \pm SD & $20.2 \pm 9.7$ & $23.6 \pm 8.5$ & \\
\hline Range (min-max) & $6.0-40.0$ & $7.0-35.0$ & \\
\hline \multicolumn{4}{|l|}{ Atypical cells (\%) } \\
\hline$\leq 4$ & $17(89.5)$ & $7(63.6)$ & \\
\hline $5-10$ & $2(10.5)$ & $4(36.4)$ & $0.049^{\mathrm{s}}$ \\
\hline Mean \pm SD & $3.0 \pm 1.2$ & $4.5 \pm 2.8$ & \\
\hline Range (min-max) & $1.0-6.0$ & $2.0-10.0$ & \\
\hline
\end{tabular}

Haematol J Bangladesh 2019; 3(2):42-46 


\section{Discussion}

This was a cross sectional, observational study carried out with an aim to observe the number of patients achieve early molecular response (EMR) after TKI therapy. A total of 30 diagnosed CML patients to TKIs was checked for quantitative BCR-ABLl (by qRT-PCR) level at 3-month of starting TKI were attended in indoor and outdoor, Department of Haematology, BSMMU, Dhaka, between February 2018 to January 2019 were included in this study. The present study findings were discussed and compared with previously published relevant studies. Majority (46.7\%) patients belonged to age 30 and 31-50 years respectively. The mean age was found $36.1 \pm 11.7$ years with range from 20 to 70 years. Similarly, Kagita et al. found their study the median age at presentation was 33 years with range $9-63$ years. ${ }^{6}$ In a study, Doval et al. showed the mean age was 41 years with range from 18 to 66 years. ${ }^{7}$ Bee et al. observed in their study that the mean age was 45.5 years with range from 30.8 to 56.2 years. 8 Etienne et al. demonstrated the median age as 56 years with range from 17 to 89 years. ${ }^{9}$

In this series it was observed that all (100.0\%) patients had splenomegaly, $22(73.3 \%)$ had anaemia and 12 (40.0\%) had hepatomegaly. In a study observed by Hasan, splenomegaly was the predominant (95\%), $90 \%$ of male and $72 \%$ of female recruited patients were anaemic at presentation and hepatomegaly (41.0\%). 10 Doval et al. observed splenomegaly in $60 \%$ and hepatomegaly in $29.0 \%$ cases. ${ }^{7}$ In this study we observed that, mean haemoglobin was $9.63 \pm 1.62$ $\mathrm{g} / \mathrm{dl}$ with a range from 6.5 to $12.7 \mathrm{~g} / \mathrm{dl}$. Similarly, Hasan also found haemoglobin $(\mathrm{Hb} \%)$ mean $( \pm \mathrm{SD})$ value by $10.4 \pm 2$ (range $5-15.3 \mathrm{~g} / \mathrm{dl}$ ) in his study. 10 Kagita et al. showed mean $\mathrm{Hb}$ was $10.9 \mathrm{gm} / \mathrm{dL}$ with a range from 6.4 to $16 \mathrm{gm} / \mathrm{dL} .6$ Marin et al. documented in their study that the median haemoglobin was 11.6 $\mathrm{gm} / \mathrm{dL}$ with range from 6.99 to $16.0 \mathrm{gm} / \mathrm{dL} .{ }^{11}$ Similarly, Doval et al. demonstrated the mean $\mathrm{Hb}$ (range grams) as $10.8 \mathrm{~g} / \mathrm{dl}$ with range from 8.1 to 16.g/dl.7 We observed that almost three fourth (73.3\%) of the patients had total leukocyte count by $101-250 \times 109 / \mathrm{L}$. The mean total leukocyte count was $175.2 \pm 90.1 \times 109 / \mathrm{L}$ with range from 3.5 to $460.0 \mathrm{x}$ 109/L. Hasan showed white blood cell (WBC) count mean $( \pm \mathrm{SD})$ was $178.5 \pm 112$ (range $24-580 \times 109 / \mathrm{L}) .10$ In $82 \%$ of patients, WBC count was $>100 \times 10 \% / \mathrm{L}$.
Kagita et al. found, in their study, the median white cell count as $145 \times 109 / \mathrm{L}$ with range from 13.8 to 308 x 109/L. 6 Marin et al. found the median leukocyte count as $139.5 \times 109 / \mathrm{L}$ with range from 5.1 to $410.9 \mathrm{x}$ $109 /$ L. ${ }^{11}$ In our study the majority $(46.7 \%)$ patients had platelet count $\leq 400 \times 109 / \mathrm{L}$; the mean was $468.5 \pm 211.6 \times 10^{9} / \mathrm{L}$ with range from 160.0 to 1000.0 x 109/L. Almost similarly, Hasan observed the mean $( \pm \mathrm{SD})$ of platelet as $412.3 \pm 282.5$ (range $70-1850 \mathrm{x}$ $109 / \mathrm{L}) .10$ In this study, almost two third $(63.3 \%)$ patients were found optimal $(\leq 10 \%)$ after 3 -month of starting imatinib. The mean after 3-month BCR-ABL 1 was found $14.96 \pm 17.36 \%$ with range from 0.10 to $72.0 \%$. Bee et al. demonstrated that the BCR-ABL 1 level at three months did not predict better OS (overall survival at ten years); patients who had a BCR-ABL 1 level $\leq 10 \%$ did not have significantly better OS than those who had a BCR-ABL 1 level $>10 \%$ at three months (100.0\% vs. $95.2 \%$, respectively; p:0.545). ${ }^{8}$ Hughes et al. consisted their study patients who achieved early molecular response (EMR) at 3 months were more likely to achieve major molecular response (MMR) by 2 years than were patients with EMR failure. ${ }^{3}$ Quintas-Cardama et al. showed that the patients with a $\mathrm{BCR}-\mathrm{ABL}_{1} / \mathrm{ABL}_{1}$ ratio greater than $1 \%$ to $10 \%$ after 3 months of imatinib had a $92 \%$ probability of achieving CCyR with continued therapy, similar to the $98 \%$ for those with $1 \%$ or less, but their risk of progression $(11 \%)$ was almost 3 -fold that of patients with a BCR-ABL $/ \mathrm{ABL}_{1}$ transcript ratio of $1 \%$ or less $(4 \%)$ and similar to that of patients with transcript levels more than $10 \%(13 \%) .12$ Kagita et al. observed their study the optimal response was $100 \%$, and no suboptimal response. ${ }^{6}$ In this study it was observed that mean haemoglobin, total leukocyte count, platelet count, basophil, myelocyte were not statistically significant $(\mathrm{p}>0.05)$ when compared between BCR-ABL $1 \leq 10 \%$ (optimal) and BCR-ABL $>10$ (warning) groups. However, mean typical cells was significantly higher in BCR-ABL $1>10$ (warning) group. Hughes et al observed their median platelet count was found $370 \mathrm{x}$ $109 / \mathrm{L}$ with range from $66-1400 \times 109 / \mathrm{L}$ in BCR-ABL 1 $\leq 10 \%$ and $362 \times 109 / \mathrm{L}$ with rang from 84 to $2232 \times$ $109 / \mathrm{L}$ in $\mathrm{BCR}-\mathrm{ABL}_{1}>10 \% .^{3}$

\section{Conclusion}

This study confirms that early molecular monitoring at 3 months after imatinib initiation helps in predicting

$$
\text { Page | } 45
$$




\section{Original Article}

the concurrent cytogenetic response and treatment optimization in CML patients.

\section{Reference}

1. Baccarani M, Cortes J, Pane F, Niederwieser D, Saglio G, Apperley J et al. Chronic myeloid leukaemia: an update of concepts and management recommendations of European Leukaemia Net. Journal of clinical oncology. 2009 Dec; 27(35):6041-6051.

2. Hanfstein B, Muller MC, Hehlmann R, Erben P, La useker M, Fabarius A et al. Early molecular and cytogenetic response is predictive for long-term progression-free and overall survival in chronic myeloid leukaemia (CML). Leukaemia. 2012 Sep; 26(9):2096-2102.

3. Hughes T, Deininger M, Hochhaus A, Branford S, Radich J, Kaeda $\mathrm{J}$ et al. Monitoring $\mathrm{CML}$ patients responding to treatment with tyrosine kinase inhibitors: review and recommendations for harmonizing current methodology for detecting BCRABL transcripts and kinase domain mutations and for expressing results. Blood. $2006 \mathrm{Jul} ; 108(1): 28-37$.

4. Radich JP. How I monitor residual disease in chronic myeloid leukaemia. Blood. 2009 Oct; 114(16):3376-3381.

5. Iacobucci I, Saglio G, Rosti G, Testoni N, Pane F, Amabile M. Achieving a major molecular response at the time of a complete cytogenetic response $(\mathrm{CCgR})$ predicts a better duration of $\mathrm{CCgR}$ in imatinib-treated chronic myeloid leukaemia patients. Clinical Cancer Research. 2006 May; 12(10):3037-3042.
6. Kagita S, Jiwtani S, Uppalapati S, Linga VG, Gundeti S, Digumarti R. Early molecular response in chronic myeloid leukaemia patients predicts future response status. Tumour Biol. 2014; 35(5):4443-4446.

7. Doval DC, Batra U, Goyal S, Sharma A, Azam S and Shirali R. Chronic myeloid leukaemia treatment with Imatinib: An experience from a private tertiary care hospital. Indian Journal of Medical and Paediatric Oncology. $2013 \mathrm{Jul}$; 34(3):182-185.

8. Bee PC, Sekaran V, Ng RRJ, Kweh TY and Gan GG. The predictive value of early molecular response in chronic myeloid leukaemia patients treated with imatinib in a single real-world medical centre in a developing country. Singapore Med J. 2017 Mar; 58(3):150-154.

9. Etienne G, Dulucq S, Nicolini FE, Morisset S, Fort MP, Schmitt A et al. Achieving deeper molecular response is associated with a better clinical outcome in chronic myeloid leukaemia patients on imatinib front-line therapy. Haematologica. 2014 Mar; 99(3):458-464.

10. Hasan KM. Evaluation of chronic myeloid leukaemia patients and their molecular responses to tyrosine kinase inhibitors in Erbil city, Iraq. Iraqi J Hematol. 2018 Jan; 7(1):1-7.

11. Marin D, Bazeos A, Mahon FX, Eliasson MD, Bua M et al. Adherence is the Critical Factor for Achieving Molecular Responses in Patients with Chronic Myeloid Leukaemia Who Achieve Complete Cytogenetic Responses on Imatinib. J Clin Oncol. 2010 May; 28:1-9.

12. Quintas-Cardama A, Kantarjian H, Ravandi F, O'brien S, Tomas D, Vidal-Senmache $G$ et al. Bleeding diathesis in patients with chronic myelogenous leukemia receiving dasatinib therapy. Cancer. 2009 Jun; 115(11):2482-2490. 